\title{
Annular subvalvular left ventricular aneurysm in Bahia, Brazil
}

\author{
Armênio Costa Guimarães, Ademar Santos Filho, Josè Pericles Esteves, Waldeck Neves \\ Abreu, Lùcia Azevedo Vinhaes, Josè Antonio de Almeida Souza, and Almerio Machado \\ From the Department of Medicine and Cardiovascular Research Laboratory, Hospital Professor Edgard \\ Santos, University of Bahia School of Medicine, Bahia, Brazil
}

Two cases of left ventricular aneurysm, a 16-year-old black boy and a 23-year-old white girl, from Bahia, Brazil, are presented. In both patients there was enlargement of the cardiac silhouette and a prominent bulge of the left inferior border. On the right oblique view a ring of calcium at the ventricular opening of the aneurysms was visualized. A left ventriculogram showed a huge aneurysm in the first case and a bulge on the lateral wall of the left ventricle in the other. Cardiac catheterization showed a rise in left and right ventricular end-diastolic pressures and in the mean pulmonary artery pressure. In the first case the contour of the right ventricular pressure curve showed a restrictive pattern. The similarities of these aneurysms with the annular submitral type described in young black Africans are stressed.

Aneurysm of the left ventricle occurring in young people is considered to be a rare condition (Abrahams et al., 1962) and has been described mainly in Nigeria, South Africa, and Uganda (Abrahams et al., 1962; Chesler et al., 1965; Poltera and Jones, 1973). These aneurysms are usually submitral or subaortic, the former being more frequent (Abrahams et al., 1962; Cockshott et al., 1967). Though the aetiology is still unknown, a congenital defect of the ventricular wall near the atrioventricular groove has been postulated as the most probable cause (Abrahams et al., 1962).

In Bahia, Brazil, where other types of cardiomyopathies similar to those found in certain areas of Africa have been described (Guimarães et al., 1971; Guimarães and Esteves, 1971), the two patients reported here are the first cases of annular subvalvular left ventricular aneurysm documented in life.

This report presents the haemodynamic alterations associated with this type of left ventricular aneurysm and is intended to contribute also to a better understanding of its geographical distribution.

\section{Clinical findings}

\section{Case reports}

Case 1 A 16-year-old black boy was admitted to the University Hospital in February 1973, for Received 24 March 1976. evaluation of a tumour of the heart. Fourteen days previously he had been admitted to another hospital with acute pneumonia and then transferred to the University Hospital. At that time a chest $x$-ray film also showed a bulge at the left inferior border of the cardiac silhouette.

On admission he was asymptomatic. He referred to occasional bouts of palpitation and dyspnoea on exertion in the recent past. On physical examination the blood pressure was $110 / 75 \mathrm{mmHg}(14 \cdot 6 / 10 \mathrm{kPa})$; the radial pulse was regular and $80 / \mathrm{min}$, and the body temperature $36 \cdot 8^{\circ} \mathrm{C}$. The neck veins were distended $2 \mathrm{~cm}$ above the supraclavicular fossa when the patient was reclining at $45^{\circ}$, and there was a prominent $a$ wave in the jugular pulse. The cardiac apical impulse was palpable at the 5 th left intercostal space over the midclavicular line. There was a loud third heart sound, a fourth heart sound, and a grade $3 / 6$ diastolic murmur, louder in middiastole, increasing on inspiration, and audible at the apex of the heart. Some crepitant râles were present at the right lung base, and a slightly tender liver was palpable $8 \mathrm{~cm}$ below the xyphoid process and $6 \mathrm{~cm}$ below the right costal margin.

Laboratory data included a haemoglobin concentration of $11.7 \mathrm{~g} / \mathrm{dl}$, serum protein of $62 \mathrm{~g} / 1$ (albumin 30 and globulin $32 \mathrm{~g} / 1$ ), and a negative tuberculin test with an original tuberculin concentration of $1: 10 \cdot 000$. 
Case 2 A 23-year-old white girl was admitted to the University Hospital in January 1975. She had a past history of episodes of fatigability, dyspnoea on exertion, cough productive of white sputum, oedema, and ascites during the past 7 years, which improved with the intermittent use of diuretics.

On physical examination the blood pressure was $120 / 80 \mathrm{mmHg}(16.0 / 10.6 \mathrm{kPa})$; the radial pulse was $100 /$ minute, regular and weak; axillary temperature was $36.5^{\circ} \mathrm{C}$. The neck veins were distended $6 \mathrm{~cm}$ above the supraclavicular fossa at $45^{\circ}$. Crepitant râles were heard at the left lung base. The cardiac apical impulse was palpable at the 5th left intercostal space, over the midclavicular line, with a left ventricular heave; a systolic heave of the anterior chest wall was palpable at the 4th intercostal space, above the apical impulse. The second sound was widely split with an accentuated pulmonary component; a loud fourth heart sound and a grade $2 / 6$ mid and late systolic murmur, radiating to the axilla, were heard at the apical area. The abdominal examination showed venous collateral circulation and moderate ascites; the liver was hard and palpable $6 \mathrm{~cm}$ below the xyphoid process and $3 \mathrm{~cm}$ below the right costal margin. The spleen was palpable $3 \mathrm{~cm}$ below the left costal margin. There was slight pedal oedema.

Laboratory data included a haemoglobin concentration of $10.0 \mathrm{~g} / \mathrm{dl}$ and serum protein of $30 \mathrm{~g} / 1$ (albumin 18 and globulin $17 \mathrm{~g} / 1$ ).

\section{Electrocardiogram}

Both cases presented a displacement to the right of the transitional zone in the praecordial leads. In Case 1 , the $R$ wave was associated with a negative $\mathrm{T}$ wave in leads V2 and V3, while in Case 2 a similar abnormality was observed in leads V2 to V5 (Fig. $1 \mathrm{~A}$ and B). Case 1 also presented a broad $\mathrm{P}$ wave $(0.12 \mathrm{~s})$ in lead III and a $\pm \mathbf{P}$ in V1, with a prolonged negative phase (Fig. $1 \mathrm{~A}$ ).

\section{Radiological findings}

On the posteroanterior chest $x$-ray film the cardiac silhouette was moderately enlarged in Case 1 and minimally enlarged in Case 2. In both cases there was a prominent bulge of the left inferior border of the cardiac shadow, the pulmonary trunk was dilated, and the pulmonary vascular markings were increased (Fig. $2 \mathrm{~A}$ and $\mathrm{C}$ ) in the right middle lobe. In Case 1 there was also a triangular density at the right middle lobe of the lung. Posterior displacement of the barium filled oesophagus was noted in the right anterior oblique position, moderate in Case 1 and minimal in Case 2 (Fig. $2 \mathrm{~B}$ and $\mathrm{D}$ ). In this latter view, in both cases, a ring of calcium could be visualized in an anterior position, at the base of the aneurysmal sac. In Case 2 this ring of calcium could also be visualized in the anteroposterior view (Fig. $2 \mathrm{C}$ ).

\section{Haemodynamic findings}

Cardiac catheterization data are presented in the Table. In both cases there was a moderate rise in the left ventricular end-diastolic pressure, severe rise in the right ventricular end-diastolic pressure, and mild rise in the mean pulmonary artery pressure. In Case 1 the pulmonary capillary pressure showed an $x$ descent of the same value as the $y$ descent and the amplitude of the $v$ wave was slightly above that of the $a$ wave; the contour of the right ventricular pulse pressure showed a restrictive pattern (Fig. 3).

\section{Angiocardiography}

Case 1 The left ventricular aneurysm was outlined by the injection of contrast medium directly into its cavity: this had an irregular contour suggesting thrombus formation (Fig. 4 A). A

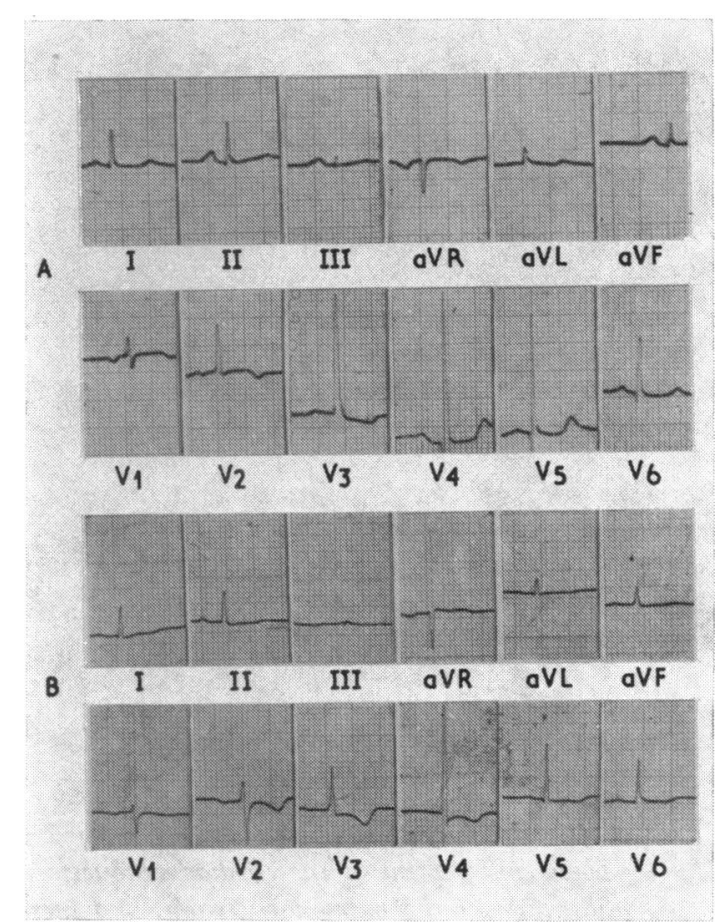

FIG. 1 Electrocardiograms of Cases 1 ( $A$ ) and 2 (B) showing displacement to the right of the transitional zone in the praecordial leads associated with primary ST T wave changes. 

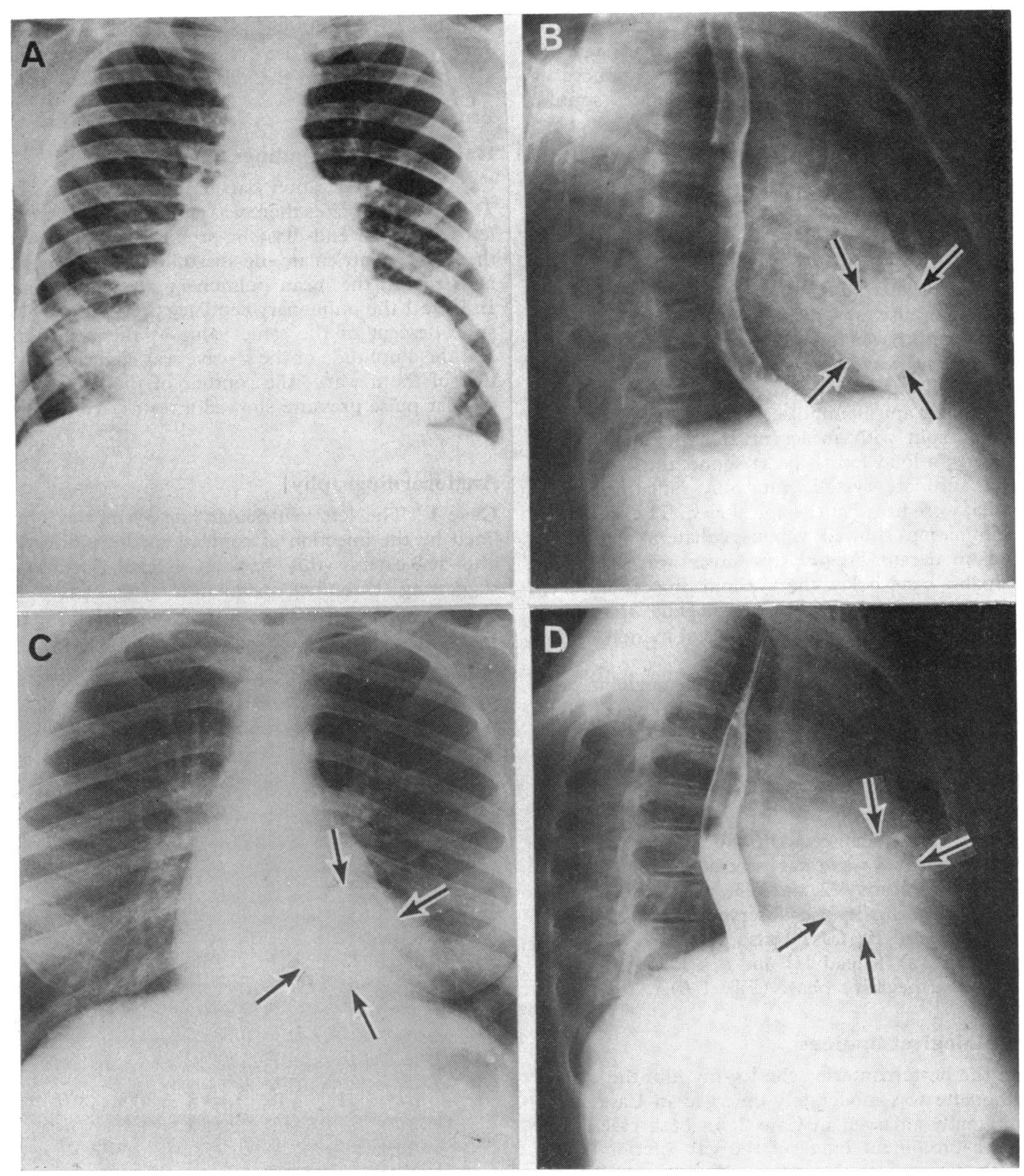

FIG. 2 Chest x-ray films of Cases 1 ( $A$ and $B$ ) and 2 ( $C$ and D). Posteroanterior view shows enlargement of the cardiac silhouette with a prominent bulge at its left inferior border, dilatation of the pulmonary trunk, and increased vascularity of the lungs. In Case 1 (A) a triangular density is also seen at the right lower lobe of the lung; ( $B$ and $D$ ) Right anterior oblique view shows posterior displacement of the oesophagus by the left atrium and a ring of calcium (between arrows) at the opening of the aneurysms into the left ventricle. In Case 2 this ring of calcium can also be visualized in the posteroanterior view (C). 
TABLE Cardiac catheterization data

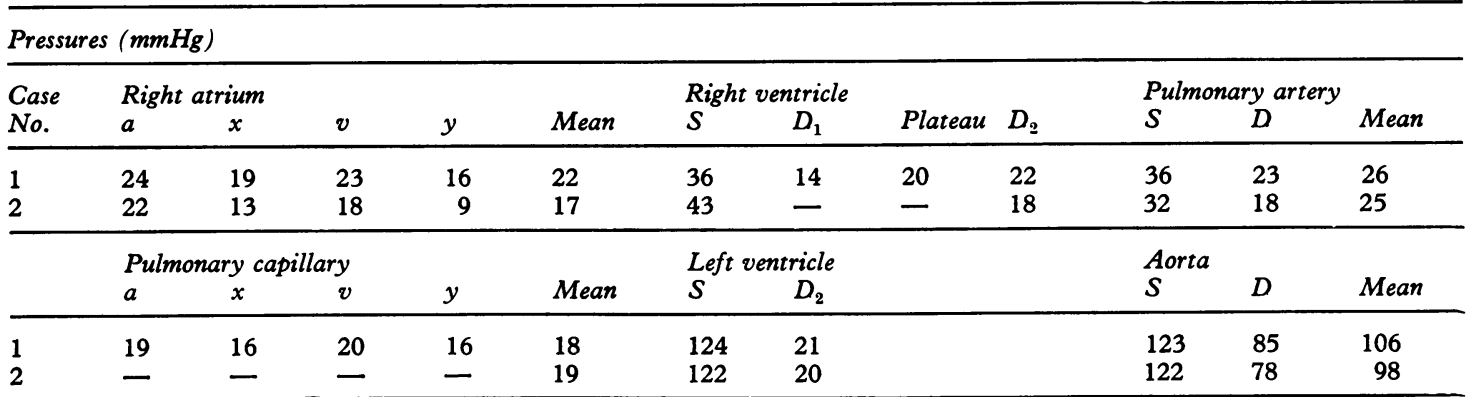

$S$, systolic; $D_{1}$, initial diastolic; $D_{2}$, end-diastolic; $D$, diastolic.

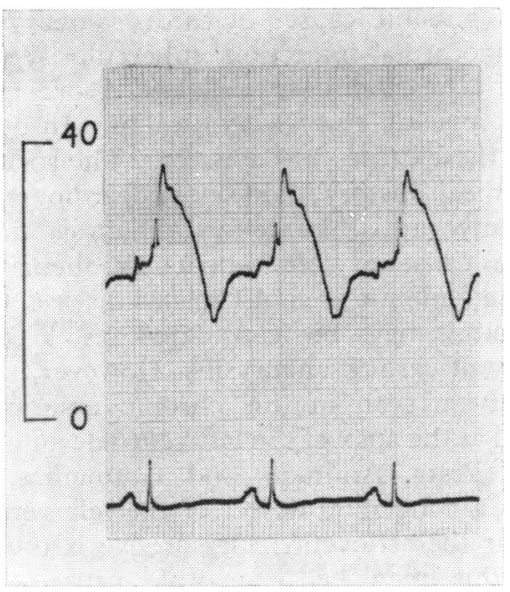

FIG. 3 Right ventricular pressure curve ( $\mathrm{mmHg}$ ) of Case 1 shows a restrictive pattern with an early diastolic dip followed by a plateau. right ventriculogram showed a triangular bulge above the apex of the right ventricle (Fig. $4 \mathrm{~B}$ ).

Case 2 A posteroanterior left ventriculogram disclosed a prominent bulge of the lateral wall of the left ventricle, corresponding to that seen on the posteroanterior chest $x$-ray (Fig. $4 \mathrm{C}$ ).

\section{Comments}

The left ventricular aneurysms reported here present all the features of the annular submitral type described in young Africans. Both our patients are from a low income social class, in which ischaemic heart disease is rarely found. In Case 1 the aneurysm was an incidental finding, while in Case 2 it was related to clinical manifestations of congestive heart failure as has been reported in the majority of the cases (Abrahams et al., 1962). Physical findings in-

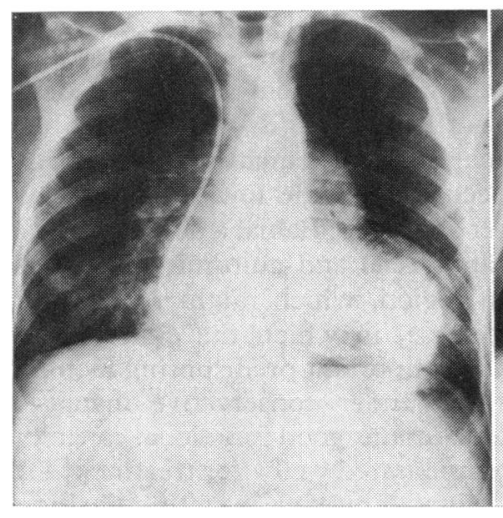

$A$

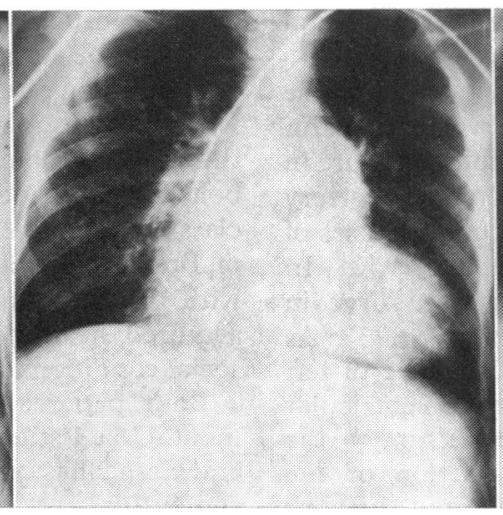

$B$

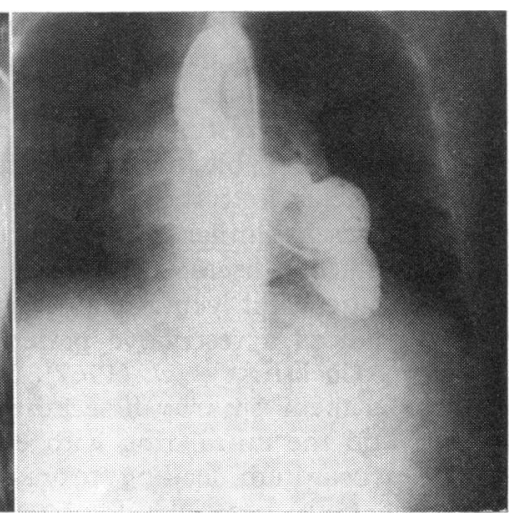

$C$

FI G. 4. Posteroanterior angiocardiograms of Cases 1 and 2. (A) Left ventriculogram of Case 1 shows a large aneurysmal sac with an irregular contour suggestive of mural thrombus; (B)

Right ventriculogram of Case 1 shows a triangular bulge above the ventricular apex; (C) Left ventriculogram of Case 2 shows a prominent bulge on the lateral wall of the ventricle. 
cluded an apical diastolic murmur in Case 1 and an apical systolic murmur in Case 2. Both types of murmurs have been previously related to blood flow through the ostia of the aneurysm (Chesler et al., 1965). The systolic murmur, in addition, may be secondary to mitral insufficiency, a complication that has been frequently documented in this condition (Cockshott et al., 1967). Case 1 did not present a systolic murmur, but the pulmonary capillary pressure fall suggested some degree of mitral regurgitation (Table).

The radiological diagnosis of the submitral type of left ventricular aneurysm such as is seen in our cases is based on (1) a localized bulge on the left cardiac border (Abrahams et al., 1962; Chesler et al., 1965; Cockshott et al., 1967), and (2) calcification in the rim of the ventricular opening of the aneurysm (Abrahams et al., 1962).

Retrograde left ventricular angiography is, however, the procedure of choice in investigating these aneurysms. Unfortunately we did not have facilities to perform serial angiographic studies and used a single film technique which did not allow proper evaluation of the dynamic aspects of the aneurysms or the demonstration of mitral regurgitation. In spite of these technical limitations, we were able to visualize a huge left ventricular aneurysm in Case 1 (Fig. $4 \mathrm{~A}$ ), while in Case 2 the injection of contrast media within the left ventricle showed only a prominent bulge on its left border (Fig. $4 \mathrm{C}$ ). In this latter patient it was not possible to outline the whole aneurysmal sac, in spite of our impression that the injection had been made into it. Two possibilities can be considered (1) that the aneurysmal sac was partially filled with thrombus or (2) that the injection outlined only a smaller aneurysm, since in this type of aneurysm the presence of several loculi is common (Cockshott et al., 1967).

The haemodynamic data documented in these two cases is interesting and deserves comment. As shown in the Table, the end-diastolic pressure in both ventricles and the main pulmonary artery pressure present similar values, as occurs in cases of restrictive heart disease (Sawyer et al., 1952). In addition, the right ventricular pressure curve in Case 1 showed a restrictive pattern (Fig. 3). As shown by Cockshott et al. (1967), this type of left ventricular aneurysm may dissect the left ventricular wall around the mitral ring with extension to the septal myocardium leading to restriction of the filling of both ventricles, as suggested by our catheterization data. A deformity of the right ventricular septal wall is suggested by the right ventriculogram of Case 1 (Fig. $4 \mathrm{~B}$ ). Since cases of right ventricular aneurysms have not yet been documented, the most probable explanation for such angiographic appearance is dissection of ventricular septum by the left ventricular aneurysm.

In some cases a moderate serous pericardial effusion may also be present (Williams, 1974). However, in our patients the angiographic appearance of the heart rules out this possibility (Fig. $4 \mathrm{~A}$ and $\mathrm{C}$ ). Some degree of constrictive pericarditis may also occur, since the pericardium is usually thickened and adherent, obliterating the pericardial cavity.

Associated endomyocardial fibrosis occurred in one of the cases reported by Abrahams et al. (1962), and can be a cause of restrictive heart disease. However, in Case 1 it was ruled out by the right ventricular angiographic findings (Cockshott, 1965).

Other possible causes of cardiac aneurysms include myocardial infarction, tuberculosis, syphilis, rheumatic heart disease, collagen disorders, myocarditis, mycotic emboli, and trauma. In our cases none of these causes was apparent. The social class, age, clinical history, and electrocardiograms excluded myocardial infarction, which is the most common cause of left ventricular aneurysm. In Bahia, an endemic area of Chagas' disease, Chagas' myocarditis may be considered as a possible aetiology of cardiac aneurysms. However, the type of aneurysm seen in this chronic myocarditis is localized at the apex of the left ventricle and is small in size (Prata, Andrade, and Guimarães, 1974). Though a congenital defect of the left ventricular wall near the atrioventricular groove is difficult to prove, this may be a possible cause of these aneurysms, as proposed by Abrahams et al. (1962). The genetic basis suggested by the susceptibility among blacks seems unlikely, since one of the cases reported by Pocock et al. (1965) and one of our cases are caucasian.

Cases of annular subvalvar left ventricular aneurysm have been reported from France, Sweden, United States, South Africa, and West Indies, but the majority come from the equatorial rain forest belt of Africa, occurring in the low social income class (Abrahams et al., 1962). Bahia, a northern state of Brazil, has many racial and cultural similarities with this African region, which might suggest an acquired heart disease, in which the climate and social conditions are important predisposing factors.

Both patients are under conservative management. Case 1 still maintains good functional capacity and Case 2 has compensated well after treatment for congestive heart failure. However, in spite of the high mortality figures for surgical resection of these aneurysms (Abrahams et al., 1962; Chesler et al., 1965; Poltera and Jones, 1973) surgery will be considered as soon as progressive deterioration takes place in either patient. 


\section{References}

Abrahams, D. G., Barton, C. J., Cockshott, W. P., Edington, G. M., and Weaver, E. J. M. (1962). Annular subvalvular left ventricular aneurysms. Quarterly fournal of Medicine, 31, 345.

Chesler, E., Joffe, N., Schamroth, L., and Meyers, A. (1965). Annular subvalvular left ventricular aneurysm in the South African Bantu. Circulation, 32, 43.

Cockshott, W. P. (1965). Angiocardiography of endomyocardial fibrosis. British fournal of Radiology, 38, 192.

Cockshott, W. P., Antia, A., Ikeme, A., and Uzodike, V. O. (1967). Annular subvalvular left ventricular aneurysms. British fournal of Radiology, 40, 424.

Guimarães, A. C., and Esteves, J. P. (1971). Idiopathic cardiomegaly in Bahia. Clinical aspects. Gazeta Médica da Bahia, 71, 21.

Guimarães, A. C., Esteves, J. P., Filho, A. S., and Macedo, V. (1971). Clinical aspects of endomyocardial fibrosis in Bahia, Brazil. American Heart fournal, 81, 7.

Pocock, W. A., Cockshott, W. P., Ball, P. J. A., and Steiner, R. E. (1965). Left ventricular aneurysms of uncertain aetiology. British Heart fournal, 27, 184.
Poltera, A. A., and Jones, A. W. (1973). Subvalvular left ventricular aneurysms. A report of 5 Ugandan cases. British Heart fournal, 35, 1085.

Prata, A., Andrade, Z., and Guimarães, A. (1974). Chagas' heart disease. In Cardiovascular Disease in the Tropics, p. 264. Ed. by A. G. Shaper, M. S. R. Hutt, and Z. Fejfar. British Medical Association, London.

Sawyer, C. G., Burwell, C. S., Dexter, L., Eppinger, E. C., Goodale, W. T., Gorlin, R., Harken, D. E., and Haynes, F. W. (1952). Chronic constrictive pericarditis: further consideration of the pathologic physiology of the disease. American Heart fournal, 44, 207.

Williams, A. O. (1974). Ventricular aneurysms. In Cardiovascular Diseases in the Tropics, p. 372. Ed. by A. G. Shaper, M. S. R. Hutt, and Z. Fejfar. B.M.A., London.

Requests for reprints to Professor Armênio Costa Guimarães, Laboratorio de Hemodinâmica, Hospital Professor Edgard Santos, Salvador, 40.000, Bahia, Brazil. 